\title{
Kadın cinselliğinde kültürel farklılıkların rolü
}

\section{The role of cultural differences in female sexuality}

\author{
Halil Çiftçi®, Eyyüp Sabri Pelit@), Bülent Katı®
}

\section{öz}

Kadınlarda cinsel yaşamın tatmini, sağlıklı ve uygun bir kişilik gelişimi için esastır, çünkü cinsel işlev bozukluğu, yaşam kalitesi üzerinde olumsuz etkisi olan yaygın bir sorunudur ve genellikle çok yönlü olup biyolojik, psikolojik, sosyokültürel ilişkili faktörler içerir. Cinsellik evrensel olmasına rağmen, cinselliğin ifadesi kültürel bağlamda göz önüne alınmalıdır, çünkü sosyal kültür, bireylerin cinsiyet tutumlarını ve kalıplarını belirleyen temel faktördür. Bu bağlamda çok sayıda çalışma, kadınların cinselliklerindeki kültürel farklılıkların rolünü belirlemiştir. Bununla birlikte, kadınlar için ayrılan kültürün modelleri ve rolleri, zaman içerisinde değişebilir. Bu yüzden, farklı kültürlerdeki insanlar için hangi cinsel sorunların öncelikli olduğunun anlaşılması önemli olup, bu kültürel değişkenliğin dikkate alınması gerekmektedir.

Anahtar Kelimeler: Kadın, cinsel yaşam, kültürel farklılık
K adın cinsel fonksiyonu fiziksel ve duyusal olayları içeren ve kişinin kendini iyi hissetmesini sağlayan karmaşık olaylar zincirini içermektedir. Kökleşmiş kültürel gelenekler, dinsel inanışlar, kadın cinsel fonksiyonunu değerlendirmek için standartlaştırılmış tanımların eksikliğinden dolayı kadın cinsel sağlığıyla ilgili literatürde geniş serileri içeren çalışmalar yoktur. ${ }^{[1]} \mathrm{Bu}$ alanda 1950 'lerin başında Masters and Johnson ve 1970'lerde Kaplan ve ark. fizyolojik ve psikolojik çalışmalara dayalı olarak kadın cinsel yanıtın döngüsünü tanımlamışlardır. ${ }^{[2,3]}$ Sınıflama birçok kez gözden geçirilmesiyle birlikte en son DSM-5'in 2013 yılında yayımlanan taslağında terminolojide değişiklikler yapılmıştır. ${ }^{[4]}$ Cinsel fonksiyon bozukluğu (CFB); farklı nedenlere bağlı cinsel uyarıya karşı oluşan arzu, uyarılma, orgazm fazlarından biri veya bir kaçının oluşmaması

Harran Üniversitesi Tıp Fakültesi, Üroloji Anabilim Dalı, Şanlıurfa, Türkiye

Yazışma Adresi / Correspondence:

Prof. Dr. Halil Çiftçi

Yenişehir Cebeci Cad Erdem Apt. No: 9, 6300 Şanlıurfa, Türkiye

Tel. $\quad$ 905369520263

E-mail: halilciftci63@hotmail.com

Gelis / Received: $\quad 09.05 .2018$

Kabul / Accepted: 01.06.2018

\section{ABSTRACT}

Satisfying sex of life in women is considered essential for a healthy and appropriate personality development because sexual dysfunction is a common distressing problem that has a negative impact on quality of life. The problem is often multifactorial that addresses biological, psychological, sociocultural factors. Although sexuality may be universal, the expression of sexuality needs to be considered within the cultural context because social culture is the essential factor specifying individuals' gender attitudes and patterns. In this context, numerous studies have documented the role of cross-cultural differences in women's sexuality. However, the models and roles of the culture allocated for women are subject to change in due course. Therefore, it is very important to understand which sexual issues are of top priority for people across different cultures, and this cultural variability needs to be taken into account.

Keywords: Woman, sexual life, cultural difference

ve cinsel ilişki sırasında ağrı olması olarak tanımlanır. Bu durum kadının kendine olan güvenini, kişiler arası ilişkilerini, evlilik ilişkisini, psikolojisini ve yaşam kalitesini etkileyen çok boyutlu bir sağlık sorunudur. ${ }^{[5,6]}$ Genel olarak kadın cinsel fonksiyon bozukluğunun prevalansı farklı tanım kriterlerine, ülkelerin farklı kültürlerine bağlı olarak birçok çalışmada farklılık göstermektedir. Bir ülkede anlamlı olan bir semptom farklı ülkenin kültürüne bağlı olarak anlamsız olabilmekte ve bu nedenle prevalans ülkeden ülkeye farklılık göstermektedir. Bu bağlamda yapılan çalışmalarda oran \%40-60 arasında değişmektedir. ${ }^{[7-9]}$ Yapılan çalışmalarda kültürel farklılık olmakla birlikte cinsel istek bozukluğu ve uyarılma bozuklukları en sık görülen cinsel işlev bozukluklarıdır. Her üç kadından birinde cinsel istek ve uyarılma bozukluğu görülebilmektedir. ${ }^{[10]}$ Yirmi dokuz ülkede 40-80 yaşlarında 13.882 kadınla yapılan çalışmaya göre kadınların \%27'sinde cinselliğe olan ilgide azalma, $\% 21$ 'inde orgazm bozuklukları, \%17'sinde lubrikasyon problemleri ve $\% 10$ 'unda disparoni saptanmıştır. ${ }^{[1]}$

\section{ETIYYoloJi}

Kadın cinsel fonksiyon bozukluğu (KCFB), fizyolojik, biyolojik, psikolojik sosyal ve kültürel bileşenleri olan çok 
boyutlu bir sağlık sorunudur. ${ }^{[12]}$ Kadındaki cinsel yanıt döngüsü tepkinin hem yoğunluğu hem de süresiyle ilişkili olup bir çok faktör etkili olmasına rağmen, yapılan çalışmalar özelikle kültürler arası farklılıklar, kronik hastalıklar, kronik ilaç kullanımları, bazı psikiyatrik rahatsızlıklar, geçmişinde seksüel travma, cinsel taciz anksiyetesi ile nörolojik, endokrinolojik diyabet ve hipertansiyon gibi kronik hastalıklar yaşam kalitesiyle ilgili sorunlar suçlanmıştır. ${ }^{[13-15]}$ Bununla birlikte KCFB halen davranışsal ve kültürel bir takım durumların ön planda olduğu düşünülmektedir. ${ }^{[16,17]}$ Cinsel işlev bozukluğu hangi nedenle başlamış olursa olsun, sürdürücü etmenlerin devreye girmesi sorunun devam etmesine neden olabilir. Yukarıda bahsettiğimiz bir takım hastalıklar ve kültürel faktörler gibi KCFB başlatıcı etkenler çözümlenmediklerinde, sorunu sürdürücü etkenlere de dönüşebilir. Devam eden ve çözülmeyen sürdürücü etkenler, sorunu performans anksiyetesine dönüştürebilir. Böylece, KCFB daha da karmaşık bir döngü haline gelebilir.

\section{Kültürel farklııklar ve kadın cinselliği}

Türk Dil Kurumu sözlüğüne göre kültür; "tarihsel ve toplumsal gelişme süreci içinde ortaya çıkan bütün maddi ve manevi değerler ve bunları sonraki nesillere iletmede kullanılan, insanın doğal ve toplumsal çevresine egemenliğinin ölçüsünü gösteren bütün araçlar veya bir topluma veya halk topluluğuna özgü düşünce ve sanat eserlerinin bütünü” olarak tanımlanmaktadır. ${ }^{[18]}$ İnsanın yaşadığı toplumun değerlerine duyarsız olması mümkün değildir. Bu nedenle, cinsiyet ve kişisel davranışlara yönelik toplum kültürünün ileri sürdüğü tutumlar ve değerler, insanlar üzerinde denetleyici, sınırlandırıcı ve rehberlik edici bir şekilde pek çok işlevi yerine getirir. Bu yönü itibariyle, aslında kadın ve erkek arasındaki farklılıklar sadece biyolojik, fizyolojik veya psikolojik değil, aynı zamanda kültüreldir. Yaşanan toplumsal kültür, insanlardan cinsiyet farklılıklarına ait rolleri yerine getirmesini beklemektedir. ${ }^{[19]}$ Kültür, kadına ve erkeğe yönelik tanımlamaları, bunlara ilişkin davranış kalıpları, cinsiyete dair kimlikler, cinslerin birbirlerine karşı olan ilişki biçimlerini düzenler. Cinsel yaşam ve cinsellik her ne kadar evrensel olsa da, kişinin çevreyle olan ilişkisinden, yaşam koşullarından ve içinde yaşadığı kültürden önemli ölçüde etkilenir ve kültür kadın cinsel yaşam tarzında önemli ve belirleyici bir rol oynar. ${ }^{[20]}$ Çeşitli şekillerde ortaya çıkan bedensel deneyimlerimizin çoğu, toplumsal etkileşim alanları içinde ortaya çıkmaktadır. Toplumsal etkileşim alanları, insan bedeni üzerinde çeşitli etkilere sahiptir. Bu söz konusu etkiler, insan bedeninin sosyal-kültürel bir varlık olarak ele alınmasına yol açmaktadır. Bu bağlamda kadın bedeninin ve cinselliğinin inşasının sosyal güçlerin bir ürünü olarak oluştuğuna inanılmaktadır. Kadına sosyalleşme sürecinde bedenini nasıl kullanması, algılaması ve nasıl davranması gerektiği öğretilir. Bu süreç içinde bulunduğu kültürel yapılanmaya göre kadın bedensel ve cinsel olarak pasifize edilmiş ya da baştan çıkarıcı, ayartıcı, beğendirilmesi gereken bedensel konumuna göre giyinmekte, yürümekte, konuşmakta, davranış ve tutum sergilemekte ve cinsel pratiklerde bulunmaktadır. ${ }^{[16]} \mathrm{Bu}$ nedenle cinsel işlev açısından "normal" kavramının kültürler arasında farklılık gösterdiğini bilmek ve cinsel sentezleme kültürel açıdan ayrı ayrı değerlendirilmesi gerekmektedir. The Global Study of Sexual Attitudes and Behavior tarafindan 29 ülkede 40-80 yaş arası kadın ve erkeği ele alan çalışmada, cinsel sorunların tüm ülkelerde yaygın olduğu, ancak bunların kültürler arasında büyük farklılık gösterdiği saptanmıştır. ${ }^{[1,21]}$ Yine, Burri ve ark.'nın prematür ejakülasyon (PE) konusunda kadın algısındaki kültürler arası farklılıkları belirlemeye yönelik çalışmalarında, üç farklı coğrafyadaki cinsel aktif, 20 ile 50 yaş arası 1463 kadın çalışmaya dahil edilmişlerdir. İtalya'dan 502, Güney Kore'den 508 ve Meksika’dan 453 kadın seçilmiştir. Bu kadınların cinsel partnerlerinin PE sorunu olan bir erkek olmasına dikkat edilmiştir. Kadın seksüel fonksiyon indeksi (FSFI), kadın seksüel sorun skalası (FSDS) ve ilişki değerlendirme ölçeği (RAS) kullanılarak kadınlar değerlendirilmiştir. PE nedeniyle oluşan cinsel sorunun derecesi ve ejakülatuvar kontrolün önemi arasında kadınlar açısından her üç ülkedeki çalışmada birbirinden anlamlı düzeyde farklılıklar saptanmıştır. Çalışmasının sonuç kısmında farklı kültürler arasında, bireyler için önemli olan cinsel sorun ve konuların hangisi olduğunun belirlenmesi, aynı problemlerin hangi kültür için ciddi bir sorun yarattığının bilinmesi ve daha iyi anlaşılması önemlidir. ${ }^{[22]}$ Tarihi seyir içerisinde, kadın cinselliği bulunduğu kültürel ve sosyal yapıya göre şekillenmiş, yeniden yapılandırılmıştır. Örneğin, geleneksel Hıristiyan öğretisi cinsellikte zevk almayı kirlenmekle eş hale gelmekle özdeşleştirmektedir. Cinsel birleşmede esas olan, çocuk yapmaktan başka bir fikre sahip olunmamasıdır. Böylece, cinsellik hep kirliliğin yanında ve kutsalın karşı tarafında yer almıştır. ${ }^{[16]}$ Orta çağlarda ise genç kızlar büyük bir baskı altında tutulur, anneler hiç bir zaman kızlarının erkeklerle oynamasına müsaade etmezlerdi. ${ }^{[23,24]}$ Ataerkil toplumlarda ise kadın cinselliğinin denetlenmesi önemli bir özelliktir. Kadınlardan beklenen rol saflı̆ı̆ı korumasıdır; kadınlar, karşı cinsle ilişkiler konusunda endişe ve utanç taşırlar. Cinsel ilgi ve aktiviteler kısıtlanır. Bazı kadınlar cinselliğin günah ve ayıp olduğu yönünde telkinlerle büyütülür. Erişkin olduktan sonra da doğal olarak hissedecekleri cinsel arzularını bastırırlar. Cinsel ilişkilerde 
sorumluluğun gelişmesine izin vermezler. Cinsel aktiviteyi başlatma ve yönlendirme yükümlülügünün erkeğe ait olduğunu ifade eden mitler, kadınların geleneksel edilgen rolünü de pekiştirmektedir. Bu mite göre, cinsel ilişki isteğinin dile getirilmesi, ilişkide arzu edilen etkinliklerin talebi bir kadın için hafiflik olarak nitelendirilmektedir. ${ }^{[25]}$ Bu konuyla alakalı olarak Mert ve ark.'nın yapmış olduğu çalışmada, kadınların \%86,2'si cinsel konuların aile içinde konuşulmadığını ifade etmiştir. Kadınların \%37,9'u cinsel konularla ilgili ilk bilgileri kız arkadaş yoluyla, \%24,1'i sevgili veya eş aracilığıyla, \%19'u ailenin aydınlatmasıyla, \%18'i basın yayın aracılığı ile öğrendiklerini bildirmişlerdir. Mastürbasyon hakkındaki görüşleri sorulduğunda, $\% 44,8$ 'i olağan-normal olarak ifade ederken, $\% 25,9$ 'u günah-ayıp olarak yorumlamıştır. ${ }^{[26]}$ Sanayi devrimi ile beraber ekonomik yapının değişmesi kadın-erkek rollerini de değiştirdi. Bunun nedeni modern ekonominin "cinsiyetsiz" yani "unisex" bir yapıyı temel almasından kaynaklanmaktadır. Bu yapı, zorunlu cinsiyet rolleri olmayan erkek ve kadın rollerini birbirinden çok fazla ayırmadığından, cinsiyetsiz bir ekonomik düşünce temel tezine dayanmaktadır. ${ }^{[16]}$ Modern toplumlarda ise beden cinsel etkinlikte birlikte dile getirilmeye başlandı. Bu değişim sonucunda bedenin anlamında kaymalar meydana geldi, bedensel sözcügünün anlamı cinsel olanla özdeşleşti. Nihayetinde, beden giderek cinsel eyleme indirgenen ve meşru bir şekilde müdahale edilen bir söylemin içine yerleştirildi. ${ }^{[16]}$ Kısaca, tarihi seyir içinde toplumsal ve gündelik yaşamda kadın bedeni ve cinselliği, kültürel ve toplumsal unsurlar tarafindan kurgulanmakta ve yeniden inşa edilmektedir.

Sonuç olarak; kadın cinselliğinin şekillenmesi, değişimi, dönüşümü ve bedensel imajı, inanç ve tutumlarından, toplumdaki ideallerden, aileden, arkadaş çevresinden, yaşadığ1 toplumsal kültürden etkilenen ve gelişimi yaşam boyu devam eden bir süreç olduğunu söyleyebiliriz. Kadın cinselliği ve bedeni ait olduğu toplumsal ve kültürel mirasın görünür kılındığı yerdir sonucuna varabilmekteyiz.

\section{Hakem Değerlendirmesi}

Dış bağımsız

Çıkar Çatışması

Yazarlar çıkar ilişkisi olmadığını beyan etmişlerdir.

\section{Finansal Destek}

Herhangi bir mali destek alınmamıştır.

\section{Peer-review}

Externally peer-reviewed.

Conflict of Interest

No conflict of interest was declared by the authors.

Financial Disclosure

No financial disclosure was received.

\section{KAYNAKLAR}

1. Ogbera AO, Chinenye S, Akinlade A, Eregie A, Awobusuyi J. Frequency and correlates of sexual dysfunction in women with diabetes mellitus. J Sex Med 2009;6:3401-6. [CrossRef]

2. Masters WH, Johnson VE, editors. Human Sexual Response, 1st ed. Boston: Lippincott Williams \& Wilkins; 1966. p.1-366.

3. Kaplan HS, editor. Disorders of Sexual Desire and Other New Concepts and Techniques in Sex Therapy. New York: Brunner-Mazel Inc.; 1979. p.1-237.

4. American Psychiatric Association. Diagnostic and Statistical Manual of Mental Disorders, 5th ed. Arlington (VA): American Psychiatric Publishing; 2013. [CrossRef]

5. Salonia A, Zanni G, Briganti A, Fabri F, Rigatti P, Montorsi F. The role of the urologist in the management of female sexual dysfunction. Curr Opin Urol 2004;14:389-93.

6. Spector IP, Carey MP. Incidence of the sexual dysfunction: a critical review of the empirical literature. Arch Sex Behav 1990;19:389-408.

7. Laumann EO, Paik A, Rosen RC. Sexual dysfunction in the United States: prevalence and predictors. JAMA 1999;281:537-44.

8. Lewis RW, Fugl-Meyer KS, Bosch R, Fugl-Meyer AR, Laumann EO, Lizza E, Martin-Morales A. Epidemiology/risk factors of sexual dysfunction. J Sex Med 2004;1:35-9. [CrossRef]

9. Nazareth I, Boynton P, King M. Problems with sexual function in people attending London general practitioners: cross sectional study. BMJ 2003;327:423. [CrossRef]

10. Oksuz E. Malhan S. Prevalence and risk factors for female sexual dysfunction in Turkish women. J Urol 2006;175:654-8. [CrossRef]

11. Laumann EO, Nicolosi A, Glasse DB, Paik A, Gingell C, Moreira E, et al. Sexual problems among women and men aged 40-80 y: prevalence and correlates identified in the Global Study of Sexual Attitudes and Behaviors. Int J Impot Res 2005;17:39-57. [CrossRef]

12. Berman JR. Physiology of female sexual function and dysfunction. Int J Impot Res 2005;17 Suppl 1:S44-51. [CrossRef]

13. Spector, IP, Carey MP. Incidence and prevalence of the sexual dysfunctions: A critical review of the empirical literature. Arch Sex Behav 1990;19:389-408.

14. Pontiroli AE, Cortelazzi D, Morabito A. Female sexual dysfunction and diabetes: a systematic review and meta-analysis. J Sex Med 2013;10:104451. [CrossRef]

15. Yilmaz H, Polat HA, Yilmaz SD, Erkin G, Kucuksen S, Salli A, Ugurlu H. Evaluation of sexual dysfunction in women with rheumatoid arthritis: a controlled study. J Sex Med 2012;9:2664-70. [CrossRef]

16. Bilgin R. Geleneksel ve modern toplumda kadın bedeni ve cinselliği. Fırat Üniversitesi Sosyal Bilimler Dergisi 2016;26:219-43.

17. Nicolosi A, Laumman EO, Glasser DB, Moreira ED Jr, Paik A, Gingell C; Global Study of Sexual Attitudes and Behaviors Investigators' Group. Sexual behavior and sexual dysfunctions after age 40: the global study of sexual attitudes and behaviors. Urology 2004;64:991-7. [CrossRef]

18. h t t p : / / w w w.tdk.gov.tr/index.php?option=com gts\&arama=gts\&guid=TDK.GTS.5b168b18dbc615.85498472 (Erişim Tarihi: 26.04.2018)

19. Ersoy E. Cinsiyet Kültürü İçerisinde Kadın ve Erkek Kimliği (Malatya Örneği). Fırat Üniversitesi Sosyal Bilimler Dergisi 2009;19:209-30.

20. Kingsberg SA, Janata JW. Female sexual disorder: assessment, diagnosis and treatment. Urol Clin N Am 2007;34:497-506. [CrossRef]

21. Montorsi F. Prevalence of premature ejaculation: a global and regional perspective. J Sex Med 2005;2 Suppl 2:96-102. [CrossRef]

22. Burri A, Graziottin A. Cross-cultural differences in women's sexuality and their perception and impact of premature ejaculation. Urology 2015;85:118-24. [CrossRef] 
23. İlksel Toplumlarda Seksüel Yaşantılar [Ceviren: Gökalp Sungurgil]. İstanbul: Yaylacık Matbaası; 1970. 79 s.

24. André Morali-Daninos. Histoire des relations sexuelles, Presses Universitaires de France; 4e éd. mise à jour edition. Çeviren: İbrahim Yakupoğlu, Cinsel İlişkiler Tarihi, İletişim Yayınları; 1980.
25. Dinç Kahraman S. Kadınların Toplumsal Cinsiyet Eşitsizliğine Yönelik Görüşlerinin Belirlenmesi. Dokuz Eylül Üniversitesi Hemşirelik Yüksekokulu Elektronik Dergisi (DEUHYO ED) 2010;3:30-5.

26. Mert DG, Erberk Özen N. Genel Psikiyatri Polikliniğine Bașvuran Kadın Hastalarda Cinsel İşlev Bozukluğu ve İlişkili Sosyokültürel Parametrelerin Değerlendirilmesi. Klinik Psikiyatri 2011;14:85-93. 